\title{
Investor Overconfidence and Stock Returns: Evidence from Pakistan
}

\author{
${ }^{1}$ Beenish Tariq, ${ }^{2}$ Naeem Ullah \\ ${ }^{I}$ Foundation University Institute of Engineering \& Management Sciences \\ ${ }^{2}$ Foundation University Institute of Engineering \& Management Sciences
}

\begin{abstract}
The study investigates investor overconfidence in Pakistan stock market. By taking daily stock prices of 27 leading companies representing all sectors of Karachi stock exchange we found that return of the securities have impact on securities' trading volumes. While trading volumes failed to impact returns in short term horizon. Further returns volatility had impact on the returns but failed to impact trading volume. This indicates that despite return volatility, overconfident Pakistani investor continue to trade in the security. Impulse response analysis exhibits that trading are impacted by one standard deviation of security return but they still remain positive and mostly stay above zero. The study was conducted in vector auto regressive environment.
\end{abstract}

Key words: Investor overconfidence, Returns, Volatility, Vector Auto regression

\section{Introduction}

The history of stock markets is full of events that made mark on the history. The crash of 1929 of U.S stock markets; Black Monday crash of 1927; Dot Com bubble burst and Crash of Asian stock exchanges in 90s; market liquidity crunch of 2007 are the events that refer to dramatic changes in stock prices and trading volumes. The standard finance models of sharpe (1964), Linter (1965) and Black (1972) were helpless in explaining these anomalies. Thus the best way to explain such phenomena is to study the behavior of the people who were at the heart of these crises. The standard flaw in these models was assumption of "rational investor" which in the world lead by perception is difficult to be found. Thus researchers of behavioral finance tried to augment them with alternative model that takes into account irrational behavior of the investor.

Delong, Shleifer, Summers, and Waldmann (1990) were the first to give the idea of investor sentiments. They posit that investors are governed by beliefs of future cash flows and not by the facts regarding risks of such future benefits. Further they argued that rational investor should not compete with sentimental investor because it's costly and risky. Thus they are unable to bring the prices to their fundamental values. Thus it's the major assumption in behavioral finance literature that there are no limits to arbitrage. The Dot Com bubble supported this theory with flying colors. The periods of enthusiastic investor sentiments pushed the price to an unprecedented level. The arbitragers were unable to correct the market because of high prices and went out of business.

Thus studying investor sentiment is they key to understand the behavior of today's stock markets. Getting in-depth knowledge of investor sentiments by digging into the factors that contribute to it, quantifying them and how they affect sentiment is of paramount importance in the research of today. The most powerful factor in this relation is investor overconfidence. Overconfidence relates to investors belief that he is precise in his prediction of stock returns and because of this misconception he continue trading (Odean ,1998a). Odean (1999) posits that those investors who trade more tends to loose more. The bullish behaviour of stock markets mistakenly leads investor to believe that his investment skills are superior. Thus he keeps on investing and raising trading volumes. Further, overconfident investor do not reduce their trading activities in the same ratio as market is declining. This tendency is responsible for higher trading volumes even in the wake of declining trend in the market.

However, investor overconfidence should not be confused with investor disposition-a tendency to sell securities in time of rising prices to gain profit and retain them in time of price drop in anticipation that loss can be avoided when prices rise again. This concept is discussed in detail in literature. Most of today's researchers are relying on investor confidence to explain market behavior. Trading volumes are taken as proxy for investor overconfidence in recent studies (see for example Shefrin and Statman, 1985; Statman et al., 2006; Goetzmann and Massimo, 2003; Odean, 1998b; Ranguelova, 2001). All these studies take into account the investor overconfidence to explain returns and vice versa. There is a debate whether returns impact on investor overconfidence or vice versa

This study will take investor overconfidence to see whether Pakistani stock market's returns are dependent on overconfidence of investors or whether returns themselves determine the trading volumes. The 
study will provide an insight into rationality of Pakistani investor and also to the best of my knowledge this is the first study that examines investor overconfidence and stock returns in Pakistan.

\subsection{Sample Selection and Data}

\section{Methodology}

The primary objective of the study is to study the relationship of investor overconfidence and stock returns. In order to achieve this objective daily data was taken from a convenient sample of 26 stocks representing all sectors of Karachi Stock Exchange (KSE) from 2003-2010. Since outstanding share information regarding particular security was calculated from company's price earnings ratio therefore the sample was constrained to 2010 as Balance Sheet Analysis published by State bank of Pakistan is available till 2010. Further 2003-2010 offer an ideal period for analysis because this period consists of KSE boom (2003-2006) and also its depression period (2007-2008) and its recovery period (2009-2010). Daily data has advantage in a way that volatility can be measured with accuracy. Also different researchers have preferred daily data when working (under Vector Autoregressive environment) with stock returns and time series data (Constantinos et al., 2010; Kumar, 2010). The stocks were selected after careful scrutiny. Care was taken to take those stocks that have maximum observations and relevant accounting data.

The data for different variables were taken from Balance Sheet Analysis (BSA) published by State Bank of Pakistan and from the website of KSE stocks.com. BSA was preferred as its an official document of the Government. The website (www.ksestocks.com) was preferred because most of websites in Pakistan offer historical data from 2007 and onwards. However the records of this website are from 2003. This enabled us to study different market conditions through different phases of market volatility.

\section{Variables and Measurements}

Following simultaneous equations were estimated in this study;

$$
\begin{aligned}
& \text { mturn }_{t}=\alpha+\sum_{k=1}^{K} \beta_{k} \text { mturn }_{t-k}+\sum_{m=1}^{m} \beta_{m} \text { mret }_{t-k}+\sum_{j=1}^{j} \beta_{j} \text { mwolt }_{t}+\varepsilon_{t} \\
& \text { Where; }
\end{aligned}
$$

mturn \& mret are market turnover and weighted return of cross section of securities at time $t$. mvolt is volatility of weighted security returns. The computational details of these variables are as follows,

$$
\text { mret }_{t}=\propto+\sum_{m=1}^{m} \beta_{m} \text { mret }_{t-k}+\sum_{k=1}^{k} \beta_{k} \text { mturn }_{t-k}+\sum_{j=1}^{j} \beta_{j} \text { mvolt }_{t}+\varepsilon_{t}
$$

\subsection{Security Turnover (mturn)}

This variable is calculated by following equation;

(3)

$$
\text { mturn }{ }_{i}=\ln \left\{\sum w_{i} t_{i}\right\}
$$

Where $\mathrm{w}_{\mathrm{i}}$ is the weight based on capitalization it is calculate by individual security capitalization(No. of outstanding shares multiply by beginning price of the share at year $t$ ) divided by sum of capitalization of all securities in the investor's portfolio.

$t_{i}$ is turnover of individual security calculated by security's trading volume ( $v o l$ ) divided by outstanding shares (os), mathematically;

$$
t_{\bar{i}}=\frac{v o l_{\bar{i}}}{o s_{i}}
$$

Since historic record of outstanding stocks of selected companies were not available on KSE stock.com, we referred to earnings per share (EPS) to find outstanding shares. The formula is as follows;

(5)

Net income is (earnings before taxes-tax provision). The figures for above formula were obtained from BSA

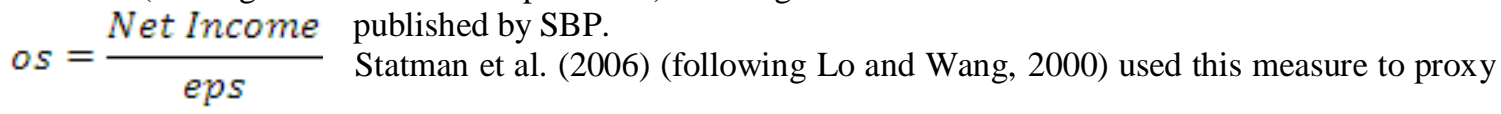


for investor overconfidence.

\subsection{Security Return (mret)}

This variable is measured by following formula;

$$
\text { mret }_{t}=\sum_{i=1}^{i} w_{i} R_{i}
$$

Where;

$w_{i}$ is the weight of security measured by capitalization of individual security divided by capitalization of all securities in investor portfolio. $R_{i}$ is security return measured by following formula;

(7)

This variable was used by Statman et al. (2006) to calculate returns of cross sections of securities. We also

$$
R_{i}=\ln \left\{\frac{R_{t}}{R_{t-1}}\right\} \text { adopted this weighted return methodology to calculate security returns. }
$$

\subsection{Security Return Volatility (mvolt)}

This variable measures the security's return risk. Ideally it is measured by standard deviation but it requires large volume of observations. However in a scenario where this availability is restricted, we can use GARCH variance series to proxy for volatility. The GARCH variance is calculates by estimating following $\operatorname{GARCH}(1,1)$ mean equation;

$$
R_{t}=\propto+R_{t-1}+\varepsilon_{t}(8)
$$

This method is superior to standard deviation in a sense that it measures volatility observation by observation. On the other hand standard deviation provides an accumulated single value for a set of observations.

\section{Analytic Model}

Vector Auto Regression (VAR) model is the most dynamic and flexible model for time series analysis. An extension of auto regressive models, its extremely useful and robust in predicting model which involve two dependent variables. Our general VAR model is of the following form;

$$
l_{t}=\propto+\sum_{j=1}^{j} \beta_{j} K_{t-j}+\sum_{m=t}^{m} \beta_{m} f_{t}+\varepsilon_{t}
$$

Where $l_{t}$ is $n \times 1$ vector of endogenous variables, which in our study is returns and turnover. While $\mathrm{ft}$ is a vector of exogenous variable at time $t$, which in our study is Return volatility. $\beta_{\mathrm{j}}$ and $\beta_{\mathrm{m}}$ are coefficients of endogenous and exogenous variables respectively. Whereas, $j$ is the number of lagged endogenous variables while $\mathrm{m}$ is the exogenous variable observation at time $\mathrm{t}$. $\mathrm{e}_{\mathrm{t}}$ captures contemporaneous correlation between endogenous and exogenous variables.

\subsection{Unit Root Test for Stationarity}

VAR can only be applied if data is stationary. Thus in order to check the stationarity of our exogenous and endogenous variables we will use Phillip Peron test for unit root analysis. All variables will be tested for stationarity at level, $1^{\text {st }}$ difference and $2^{\text {nd }}$ difference under assumption of intercept, without intercept but trend and with no intercept or trend.

\subsection{Optimal Lag Selection}

Optimal lag of exogenous variable is very important in VAR analysis. We will us Akike information criteria to find optimal lag of exogenous variables. This will be done by conducting VAR at different level of lags and the level which provides lowest score for above criterion will be used as lag value for endogenous variables.

\subsection{Unrestricted VAR}

Unrestricted VAR model will be carried out if no co integrating equations are found. However, if co integrating equation is found, then we will conduct our analysis using unrestricted VAR.

\subsection{Impulse Response Function}

Impulse response analysis is possible with VAR. they provide the impact of 1 Standard Deviation change in one variable (impulse) on the behavior of other variable (response). 


\subsection{Granger Causality}

In order to find whether turnover impacts return or return has impact on turnover, we will conduct Granger causality under following hypothesis;

$\mathrm{H}_{\mathrm{o}}$ : mret (returns) granger cause mturn (turnover)

$\mathrm{H}_{0}$ : mturn granger causes mret

The p-values of .05 or less will imply that we will reject the null hypothesis.

\subsection{Descriptive Statistics}

\section{Results and Discussion}

Table 1: Descriptive Statistics

\begin{tabular}{|lccc|}
\hline \hline & MRET & MTURN & MVOLT \\
\hline \hline Mean & 0.000781 & 8.276102 & 0.000785 \\
Median & 0.002824 & 8.194212 & 0.000266 \\
Maximum & 0.114718 & 11.27925 & 0.046101 \\
Minimum & -0.432656 & 5.440353 & $9.53 E-05$ \\
Std. Dev. & 0.024437 & 0.915504 & 0.003067 \\
Skewness & -9.177473 & 0.321462 & 10.50214 \\
Kurtosis & 159.6984 & 3.085703 & 128.2590 \\
Jarque-Bera & 659619.4 & 11.14842 & 427471.6 \\
Probability & 0.000000 & 0.003794 & 0.000000 \\
Observations & 636 & 636 & 636 \\
\hline \hline
\end{tabular}

Table 1 represents descriptive statistics of the data. The mean value of returns is .000781 with minimum $-.432 \%$ and maximum of 0.1147 . Total observation of cross sectional weighted returns, volatility and turnover is 636 each. The turnover has a mean of 8.26 this is due to the fact that turnover of large companies is large. Further it has no negative value as turnover technically cannot be negative. Higher turnover mean and lower mean of returns indicates that even in lower returns, the investors are investing and hence security turnover is increasing.

\subsection{Unit Root Test}

The Phillip Peron unit root test indicated that returns (mret) and volatility (mvolt) were stationary at level under all assumptions. However, the mturn was found non stationary at level when the test was conducted under "no intercept and no trend" assumption. However, it was stationary under all assumptions when test was conducted by taking its first difference. Thus we present following results of Philip Peron unit root test;

Table 2: Unit Root Results

\begin{tabular}{|l|l|}
\hline Variables & Stationary (Under all assumptions) \\
\hline Mret (Returns) & Level \\
\hline Mvolt (Return's Volatility & Level \\
\hline Mturn (Turnover) & $1^{\text {st }}$ Difference \\
\hline
\end{tabular}

The test clearly indicates that variables are stationary at different levels, thus co-integration analysis is not possible and hence no co-integrating equation is possible. This indicates that we will use VAR in unrestricted form and Vector error correction is not possible.

\subsection{Vector Auto regression}

Prior research did not specify any hard and fast criteria for lag criteria. Thus we let our data to determine its lags. The Akike information criteria is used to determine lag of endogenious variables. The results of VAR were repeated up to 12 lags and it was found that at lag 5 the Akike information criteria was at its lowest value, Thus we took lag=5. The VAR conducted at 5 lags of endogenous variables outlined following results; 


\begin{tabular}{|c|c|c|c|c|c|c|}
\hline & & Table 3 & AR Re: & & & \\
\hline & & & & Turnover & & \\
\hline & & $\mathrm{n}-1$ & $n-2$ & $n-3$ & $n-4$ & $n-5$ \\
\hline Mturn & coeff & 0.454228 & 0.168317 & 0.103325 & 0.110656 & 0.098654 \\
\hline & se & 0.04142 & 0.04483 & 0.04502 & 0.04429 & 0.04036 \\
\hline & $\mathrm{t}$-values & 10.9655 & 3.7547 & 2.29523 & 2.49833 & 2.44418 \\
\hline Mret & coeff & 1244 & 0.000526 & 0.000404 & 0.000293 & 110 \\
\hline & se & 0.00235 & 0.04483 & 0.00255 & 0.00251 & 0.00229 \\
\hline & $\mathrm{t}$-values & 0.52976 & -0.20673 & 0.1583 & -0.11656 & 0.04808 \\
\hline Constant & coeff & 0.519368 & 0.519368 & 0.519368 & 0.519368 & 0.519368 \\
\hline & se & 0.17401 & 0.17401 & 0.17401 & 0.17401 & 0.17401 \\
\hline & $\mathrm{t}$-values & 2.98478 & 2.98478 & 2.98478 & 2.98478 & 2.98478 \\
\hline Mvolt & coeff & 11.57806 & 11.57806 & 11.57806 & 11.57806 & 11.57806 \\
\hline & se & 7.32636 & 7.32636 & 7.32636 & 7.32636 & 7.32636 \\
\hline & $\mathrm{t}$-values & 1.58033 & 1.58033 & 1.58033 & 1.58033 & 1.58033 \\
\hline & & & & Mret & & \\
\hline & & $\mathrm{n}-1$ & $n-2$ & $n-3$ & $n-4$ & $n-5$ \\
\hline Mturn & coeff & 0.341744 & -0.74671 & 0.479011 & -0.34153 & -0.79801 \\
\hline & se & 0.81756 & 0.8098 & 0.77919 & 0.75653 & 0.73429 \\
\hline & $\mathrm{t}$-values & 4.08747 & -0.92209 & -1.89815 & -0.45144 & -1.08678 \\
\hline Mret & coeff & 61813 & -0.02342 & 0.02521 & 0.046099 & 0.084472 \\
\hline & se & 0.04636 & 0.04592 & 0.04419 & 0.0429 & 0.04164 \\
\hline & $\mathrm{t}$-values & 1.33328 & -0.50997 & -0.57054 & 1.07455 & 2.02866 \\
\hline Constant & coeff & 0.007771 & 0.007771 & 0.007771 & 0.007771 & 0.007771 \\
\hline & se & 0.00987 & 0.00987 & 0.00987 & 0.00987 & 0.00987 \\
\hline & $\mathrm{t}$-values & -0.78753 & -0.78753 & -0.78753 & -0.78753 & -0.78753 \\
\hline Mvolt & coeff & 0.770784 & 0.770784 & 0.770784 & 0.770784 & 0.770784 \\
\hline & $\mathrm{Se}$ & 0.41546 & 0.41546 & 0.41546 & 0.41546 & 0.41546 \\
\hline & $\mathrm{t}$-values & 1.85526 & 1.85526 & 1.85526 & 1.85526 & 1.85526 \\
\hline
\end{tabular}

The results of the VAR conclude that turnover is in high correlation with its previous value. Thus yesterdays turn over has impact on today's turnover. This indicates that investor overconfidence keeps the turnover at higher level despite the fact that this rise in turn over has no impact on returns. Further it is observed that return volatility has significant impact on returns but it hasn't got any significant impact on turnover. This may indicate that over confidence of the investors do not account for the risk associated with the return of the security and volumes are not impacted by return's volatility.

The second parts of these results indicate that previous days returns have significant positive impact on today's turnover. However no evidence is found of the correlation between returns and turnover in later period. The significance of returns on turnover indicates that lag of returns determine the turnover in market. This indicates that previous day's return determines to today turn over. The results also confirm that Pakistani stock market investors have imperfect knowledge of the market and perfect market hypothesis does not hold.

\subsection{Impulse Response Function (IRF)}

Impulse response function is only possible in VAR. this analysis graphically presents the behavior of the endogenous variable regarding a shock from the behavior of other endogenous variable. Following IRF graphs have been taken to predict future 30 days behavior of turnover and return

Figure 3: Response to One S.D. Innovations \pm 2 S.E. 
The graph shows the impact of 1 SD deviation movement (upward) of return on return. The graph indicates that return are positive in the beginning but then start landing in negative territory by eventually getting equal to zero.

Response of MRET to MRET

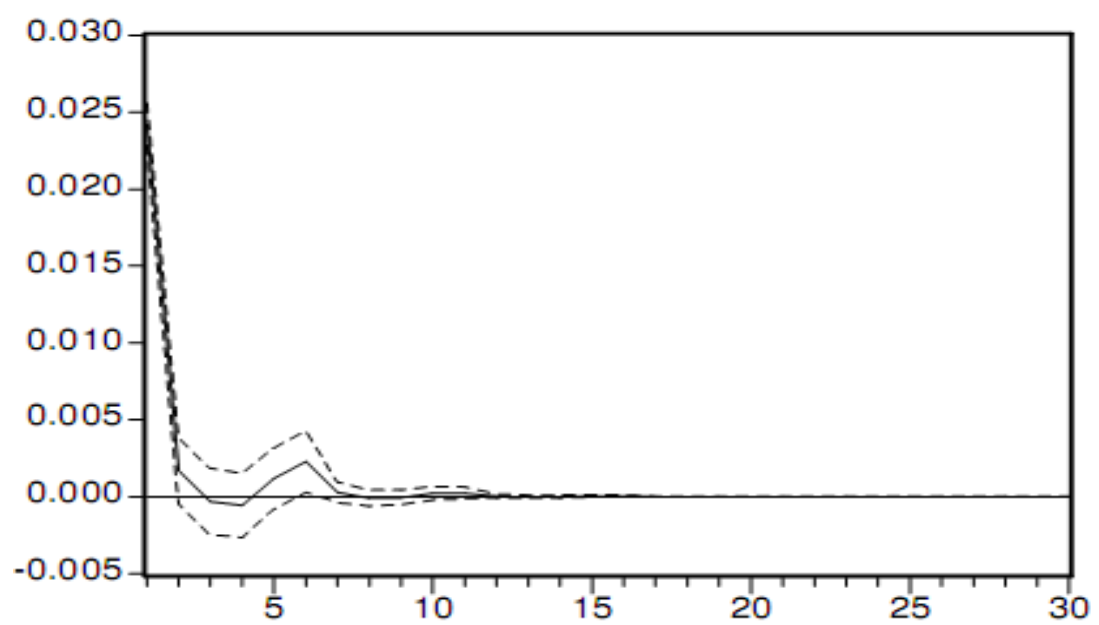

Figure 4: Response to One S.D. Innovations \pm 2 S.E.

This graph indicates the shock of returns (impulse) on turnover (Response). The graph indicates that turnovers are impacted by returns and the shock of return impacts them but they stay in positive territory. This indicates that investors do react to shocks in returns but their overconfidence, translated in terms of turn over, will keep volumes in positive territory.

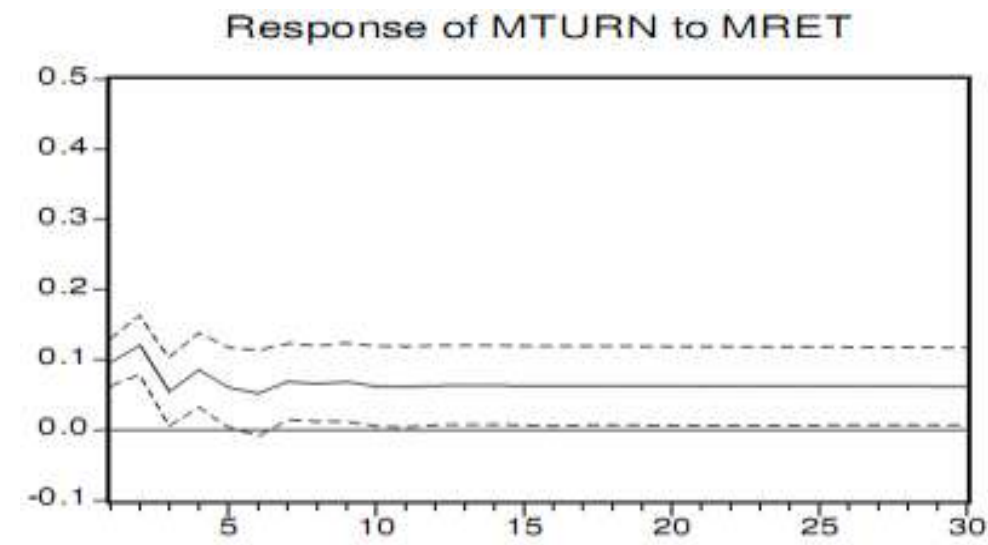

Response of MRET to MTURN

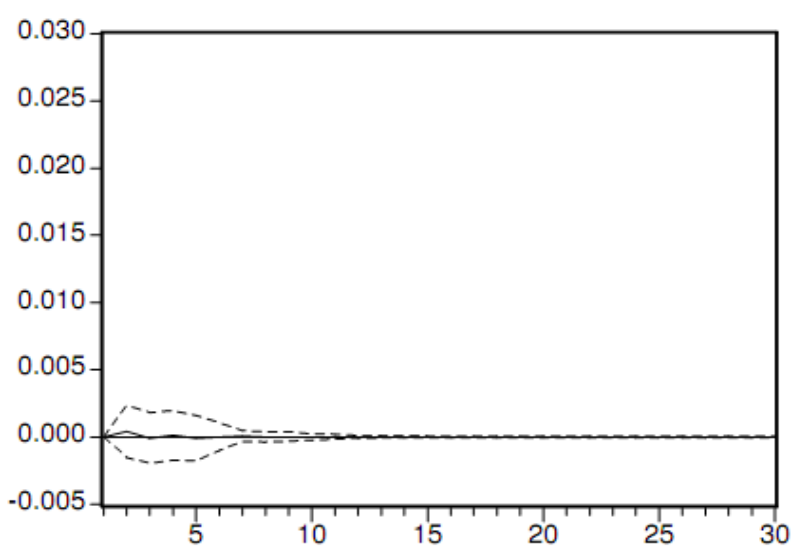

Figure 5: Response to One S.D. Innovations \pm 2 S.E. 
This figure indicates that future returns are almost unaffected by change in turn over in Pakistan. The line is mostly flat and indicates that returns do not show much movement in response to change in $1 \mathrm{SD}$ of turnover.

5.5 Granger Causality

Granger causality test is conducted along side VAR. This test roughly validates the results of VAR. However this is not conducted for such purpose. Its purpose is to detect bi causality. By using 5 lags of endogenous variables, we granger cause endogenous variables. The results are displayed as follows;

Sample: 1,636

\section{Pair wise Granger Causality Tests}

\begin{tabular}{|lccc|}
\multicolumn{4}{c}{ Lags: 5 } \\
\hline \hline Null Hypothesis: & Obs & F-Statistic & Probability \\
\hline \hline MTURN does not Granger Cause MRET & 631 & 0.30949 & 0.90732 \\
MRET does not Granger Cause MTURN & & 4.40141 & 0.00060 \\
\hline
\end{tabular}

The first null hypothesis is accepted as it has values more than probability more than .05 and F-score is 4.41 . Thus granger test reveal that turnover has no impact on returns. The second null hypothesis is accepted because it has F-values of 4.41 and $p$ values are less than .05. thus we reject null hypothesis and confirm that returns has impact on turnover. This result is in conformity with our findings

\section{Discussion}

The study was conducted in order to determine whether investor overconfidence impacts return and vice versa. The study is a deviation from standard finance models as it indicates that there are non-systematic components that impacts returns. However VAR analysis confirmed that returns impact turnover. The results indicated that previous days returns have impact on today's turnover.

This study indicates that Pakistani investor keep an eye on returns of the security. If they expect that over all the returns are increasing, they flock towards market and in ignorance increases the turn over of market. The impulse response function indicates that even when there is a risk in returns of the portfolio, the turnover experience a shock but yet stay in positive territory. This overconfidence may lead to irrational decision making by the investor and will suffer a loss. The impulse response function predicts that returns are reverting to zero and yet the turnover is high. This will lead to correction in market and investor will suffer loss.

This paper has implications for policy makers. Investors laboring under overconfidence should discuss with professional and seek advice. Further they need to adjust their positions in different stocks where turnover and returns are balanced and turnover does not deviate more than returns.

\subsection{Future Research}

Due to time, data and cost constraints we took 26 securities for our analysis. However future study may be conducted by taking all the stocks of market and conducting VAR analysis. Also we have taken only volatility as control variable, other factors such as GDP and Exchange rate, proven to have impact on stock prices can also be taken for analysis.

\section{References}

[1] Barber, B.M. \& Odean, T. (2001). Boys Will Be Boys: Gender, Overconfidence and Common Stock Investment. The Quarterly Journal of Economics, 116 (1), 261-292.

[2] Benos, A. (1998). Aggressiveness and Survival of Overconfident Traders. J Financ Market, 1, 353-383.

[3] Black, F. (1972). Capital Market Equilibrium with Restricted Borrowing. Journal of Business, 45, 444-455.

[4] Chordia, T. \& Swaminathan, B. (2000). Trading Volume and Cross-Autocorrelation in Stock Returns. The Journal of Finance, 55, 913-935.

[5] Constantinos,K., Ektor,L.A. \& Dimitrios,M. (2010). Oil Price And Stock Market Linkages In A Small And Oil Dependent Economy: The Case Of Greece, The Journal of Applied Business Research, 26, 56-63.

[6] Cooper, M. (1999). Filter Rules Based on Price and Volume in Individual Security Overreaction. The Review of Financial Studies, 12, 901-935.

[7] Daniel, K. Hirshleifer, D. \& Subrahmanyam, A. (1998). Investor Psychology and Security Market Under and Overreactions." Journal of Finance, 53(6), 1839-85.

[8] De Bondt, W., \& Thaler, R.(1985). Does the Stock Market Overreact?. Journal of Finance, 60(3), 793-805.

[9] García, D., Sangiorgi, F. \& Urosevic, B. (2007). Overconfidence and Market Efficiency with Heterogeneous Agents. Economic Theory, 30(2), 313-336

[10] Gervais, S. \& Odean, T. (2001). Learning to be Overconfident. The Review of Financial Studies, 14, 1-27.

[11] Gervais,S., Kaniel,R. \& Mingelgrin, D. (2001). The High-Volume Return Premium. The Journal of Finance, 56, 877-919.

[12] Goetzmann, W., \& Massimo, M. (2003). Disposition Matters: Volume, Volatility and Price Impact of a Behavioral Bias. Yale ICF Working Paper No. 03-01, Yale University. 
[13] Grether, D. (1980). Bayes Rule as a Descriptive Model: The Representativeness Heuristic. Quarterly Journal of Economics, 95(4), 537-555.

[14] Harris, M. \& Raviv, A. (1993). Differences of Opinion make a Horse Race. The Review of Financial Studies, 6, 473-506.

[15] Kahneman, D. \& Tversky, A. (1973). On the Psychology of Prediction. Psychological Review, 80(2), 237-251.

[16] Kumar, M. (2010). A Time-Varying Parameter Vector Autoregression Model for Forecasting Emerging Market Exchange Rates. International Journal of Economic Sciences and Applied Research, 3 (2), 21-39.

[17] Lintner, J. (1965). Security prices, Risk and Maximal Gains from Diversification. Journal of Finance, 20, 587-616.

[18] Lo, A. and J. Wang. (2000). Trading Volume: Definitions, Data Analysis, and Implications of Portfolio Theory. The Review of Financial Studies, 13, 257-300.

[19] Odean, T. (1998b). Are Investors Reluctant to Realize Losses?, Journal of Finance, 53, 1775-1798.

[20] Odean, T. (1999). Do Investors Trade Too Much?, American Economic Review, 89, 1279-1298.

[21] Odean,T. (1998). Volume, Volatility, Price and Profit when all Traders are Above Average. Journal Offinance, L111, 1887-1934.

[22] Ranguelova, E. (2001). Disposition Effect and Firm Size: New Evidence on Individual Trading Activity. Working paper, Harvard University.

[23] Shalen, C. (1993). Volume, Volatility, and the Dispersion of Beliefs. Review of Financial Studies, 6, 405-434.

[24] Sharpe, W. F. (1964). Capital Asset Prices: A Theory of Market Equilibrium under Conditions of Risk. Journal of Finance, 19, 425442.

[25] Statman, M., Thorley, S. \& Vorkink, K. (2006). Investor Overconfidence and Trading Volume. The Review of Financial Studies, 19(4), 1531-1565.

[26] Wang, F.A. (2000). Overconfidence, Investor Sentiment and Evolution. Journal of Financial Intermediation, 10, 138-170. 